Rev. Saude puibl., S. Paulo

$6: 125-33,1972$

\title{
ANEMIA FERROPRIVA EM POPULAÇÕES DA REGIÃO SUL DO ESTADO DE SÃo PAULO*
}

\section{RSPSP-124}

SzARFARC, S. C. - Anemia ferropriva em populações da região sul do Estado de São Paulo. Rev. Saúde públ., $S$. Paulo, 6:125-33, 1972.

RESUMo: Foi feito um levantamento da ocorrência de anemia ferropriva no Vale do Ribeira, nas localidades de Iguape, Apiaí, Ribeira, Barra do Chapéu e Pontal do Ribeira, através de dosagens, no sangue, de Hemoglobina, Hematocrito, Ferro sérico e Capacidade de Ligação de Ferro. Na mesma amostra populacio. nal, pelo estudo da composição dos alimentos consumidos, foi obtida a ingestão de ferro, média, diária, "per capita" nas seis localidades referidas. Os resultados da adequação de consumo foram: em Iguape, $91 \%$ : Pontal do Ribeira, $63 \%$; Icapara, 81\%; Apiai, 122\%; Ribeira, 99\% $e$ em Barra do Chapéu, 125\%. Através dos indices aplicados, evidenciou-se a existência de anemia como problema de Saúde Pública na grande maioria das áreas estudadas.

UNITERMOS: Anemia ferropriva ; População*; Sẫo Paulo, Brasil".

\section{IN T ROD U C AO}

O governo do Estado de São Paulo vem, há alguns anos, dirigindo sua atenção para o desenvolvimento da área sul de São Paulo - o Vale do Ribeira que é tida como uma das zonas menos desenvolvidas desse Estado. Vários con-
Sophia Comblüth SZARFARC **

vênios tềm sido firmados com departamentos da Universidade de São Paulo, que se propõem a estudar a região, conhecer seus problemas e desenvolver programas. O Departamento de Nutrição da Faculdade de Saúde Pública, está integrado nesse plano de desenvolvimento do Vale do Ribeira. Nesse sentido, nos propusemos a estudar a ocorrência de anemia ferropriva em populaçōes litorâneas dessa região - Iguape, Pontal do Ribeira e Icapara e em Apiaí, Ribeira e Barra do Chapéu - situados no extremo sul do Vale do Ribeira - levando-se em conta que a anemia constitui problema de saúde pública dos mais importantes entre nós.

\section{MATERIAL E METODOS}

A amostra da população foi casual simples por conglomerado (família). Dessa amostra foi retirada uma sub-amostra com unidade àmostral indivíduo para verificar a ocorrência de anemia ferropriva (Tabela 1).

A residência sorteada foi visitada e de todos os seus moradores foi tirada uma amostra de sangue para exame. Foram feitas dosagens de hemoglobina, hematócrito, ferro sérico 1 e capacidade de ligação de ferro ?.

* Trabalho realizado com auxilio financeiro do Serviço do'Vale do Ribeira e da Superintendêncía do Planejamento, Avaliação, Pesquisas e Programas Especiais do Ministério da Saude.

** Do Departamento de Nutrição da Faculdade de Saúde Pública da USP. - Av. Dr. Arnaldo, 71ら - São Paulo, SP, Brasil. 
SZARFARC, S. C. - Anemia ferropriva em populaços da região sul do Estado de são Paulo. Rev. Saúde públ., S. Paulo, 6:125-33, 1972.

\section{T A B ELA 1}

Amostra da população das localidades do Vale do Ribeira por conglomerado (familia)

\begin{tabular}{|c|c|c|c|c|c|c|}
\hline \multirow[t]{2}{*}{ Localidades } & \multicolumn{2}{|c|}{ Total de familias } & \multicolumn{2}{|c|}{$\begin{array}{cc}\text { Amostra sorteada } \\
\text { inquérito alimentar }\end{array}$} & \multicolumn{2}{|c|}{$\begin{array}{c}\text { Sub-amostra } \\
\text { sorteada } \\
\text { inquérito } \\
\text { clínico-bioquímico }\end{array}$} \\
\hline & n.o & $\%$ & n. & $\%$ & n.o & $\%$ \\
\hline Iguape & 1375 & 100 & 338 & 24.2 & 60 & 4,4 \\
\hline P. do Ribeira & 56 & 100 & 56 & 100 & 22 & 39,3 \\
\hline Icapara & 103 & 100 & 108 & 100 & 41 & 39,8 \\
\hline Apiaí & 654 & 100 & 98 & 15 & 21 & 3,2 \\
\hline Ribeira & 156 & 100 & 28 & 18 & 14 & 9,0 \\
\hline B. Chapéu & 156 & 100 & 28 & 18 & 14 & 9.0 \\
\hline
\end{tabular}

R E SU L T A D O S

Os resultados obtidos na dosagem de hemoglobina encontram-se na Tabela 2 e na dosagem de hematócrito, na Tabela 3.

TABELA 2

Niveis de hemoglobina, em gramas, por $100 \mathrm{ml}$, nas comunidades estudadas do Vale do Ribeira, $1969-1970$.

\begin{tabular}{|c|c|c|c|c|c|c|}
\hline Localidade & $\mathrm{Hb} \mathrm{g} \%$ & $₹ 10$ & $>10=12$ & $>12 \rightleftharpoons 15$ & $>15$ & TOTAL \\
\hline \multirow{2}{*}{ Iguape } & n. & 30 & 99 & 91 & 36 & 256 \\
\hline & $\%$ & 11 & 39 & 36 & 14 & 100 \\
\hline \multirow{2}{*}{$\begin{array}{l}\text { P. do } \\
\text { Ribeira }\end{array}$} & n. ${ }^{\circ}$ & 35 & 35 & 12 & 4 & 86 \\
\hline & $\%$ & 41 & 41 & 14 & $\mathbf{5}$ & 100 \\
\hline \multirow{2}{*}{ Icapara } & n.o & 54 & 51 & 13 & 0 & 118 \\
\hline & $\%$ & 46 & 43 & 11 & 0 & 100 \\
\hline \multirow{2}{*}{ Apiai } & n.o & 3 & 3 & 38 & 24 & 68 \\
\hline & $\%$ & 4 & 4 & 56 & 35 & 99 \\
\hline \multirow{2}{*}{ Ribeira } & n.o & 6 & 7 & 40 & 17 & 70 \\
\hline & $\%$ & 9 & 10 & ธ7 & 24 & 100 \\
\hline \multirow{2}{*}{$\begin{array}{l}\text { Barra do } \\
\text { Chapéu }\end{array}$} & n. ${ }^{\circ}$ & 0 & 0 & 22 & 19 & 41 \\
\hline & $\%$ & 0 & 0 & 54 & 46 & 100 \\
\hline
\end{tabular}


SZARFARC, s. C. - Anemia ferropriva em populaçбes da região sul do Estado de săo Paulo. Rev. Saude públ., S. Paulo, 6:125-33, 1972.

TABELA 3

Níveis de hematócrito em amostra populacional nas comunidades de Iguape, Pontal do Ribeira e Icapara, 1969 e Apaiai, Ribeira e Barra do Chapé, 1970.

\begin{tabular}{|c|c|c|c|c|c|}
\hline Localidade & Ht $\%$ & $<33$ & 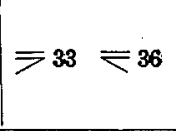 & $>36$ & TOTAL \\
\hline \multirow{2}{*}{ Iguape } & n. ${ }^{\circ}$ & 38 & 29 & 192 & 255 \\
\hline & $\%$ & 15 & 9 & 75 & 99 \\
\hline \multirow{2}{*}{$\begin{array}{l}\text { P. do } \\
\text { Ribeira }\end{array}$} & n. ${ }^{\circ}$ & 16 & 20 & 49 & 85 \\
\hline & $\%$ & 19 & 24 & 58 & 101 \\
\hline \multirow{2}{*}{ Icapara } & n.0 & 36 & 21 & 56 & 113 \\
\hline & $\%$ & 32 & 19 & 50 & 101 \\
\hline \multirow{2}{*}{ Apial } & n. ${ }^{\circ}$ & 11 & 7 & 49 & 67 \\
\hline & $\%$ & 16 & 10 & 73 & 99 \\
\hline \multirow{2}{*}{ Ribeira } & n. ${ }^{\circ}$ & 12 & 20 & 37 & 69 \\
\hline & $\%$ & 17 & 29 & 54 & 100 \\
\hline \multirow{2}{*}{$\begin{array}{l}\text { Barra do } \\
\text { Chapéu }\end{array}$} & n." & 4 & 6 & 31 & 41 \\
\hline & $\%$ & 10 & 15 & 76 & 101 \\
\hline
\end{tabular}

Estudando os níveis de hemoglobina $\theta$ hematócrito segundo um grupo etário (estatística $\chi^{2}$ com $5 \%$ de nível de significância), aceitamos a hipótese de dependência entre incidência de valores baj- xos de hemoglobina e hematócrito e idades menores do que 10 anos.

As tabelas 4 e 5 traduzem essa distribưção. 
SZARFARC, S. C. - Anemia ferropriva em populaçסes da regiăo sul do Estado de São Paulo. Rev. Saride públ., S. Paulo, 6:125-33, 1972.

\section{TABELA 4}

Distribuicăo dos individuos segundo uma ldade e um nível de hemoglobina, nas localidades de Iguape, Pontal do Ribeira e Icapara, 1969 e Apiai, Ribeira e Barra do Chapeu, 1970.

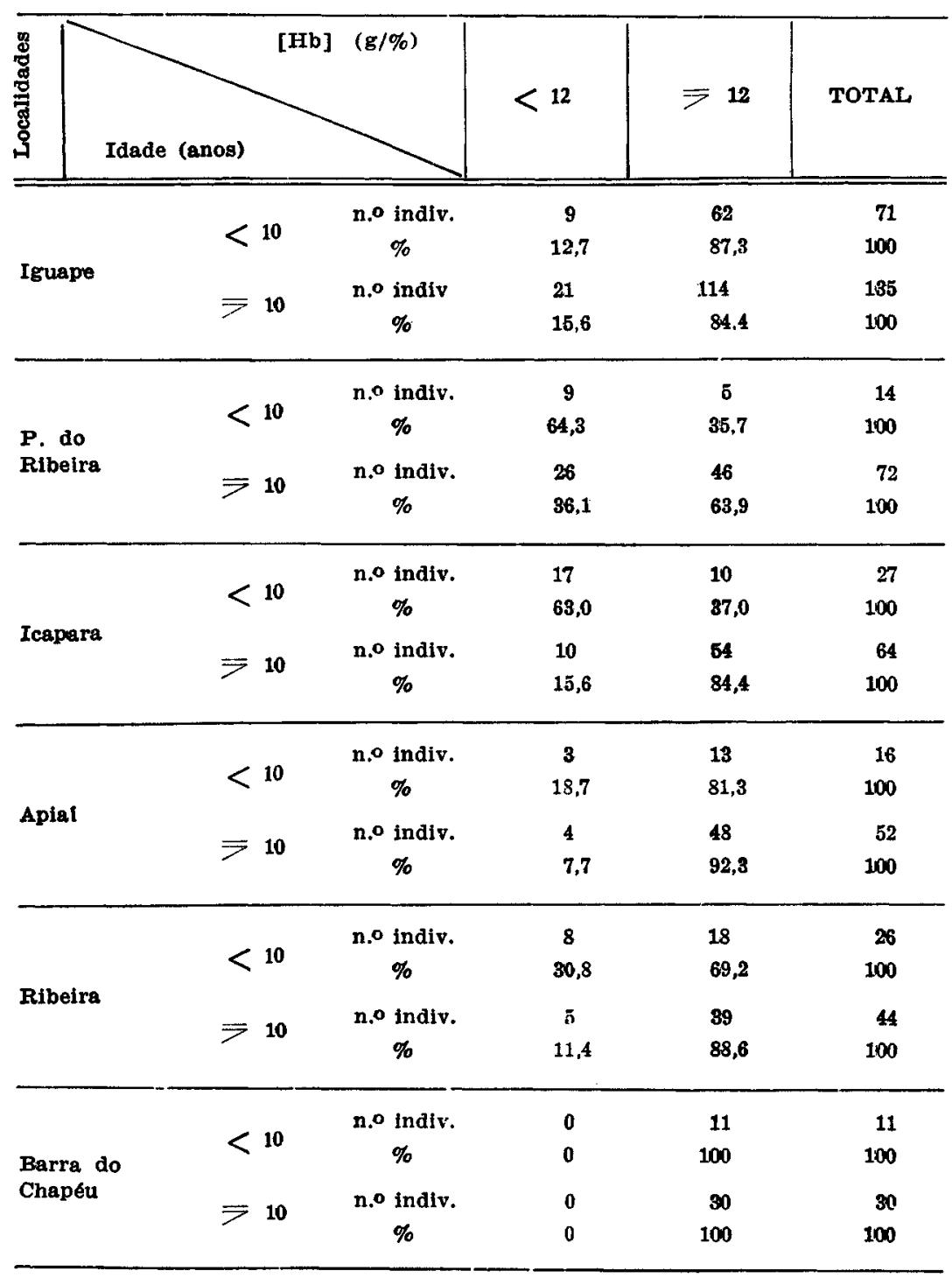


SZarfarc, S. C. - Anemia ferropriva em populaç⿸丆es da regiăo sul do Estado de såo Paulo. Rev. Saúde puibl., S. Paulo, 6:125-33, 1972.

TABEL 5

Distribuiçăo de individuos segundo uma idade e um valor de hematócrito, nas localldades estudadas do Vale do Ribeira, 1969 e 1970.

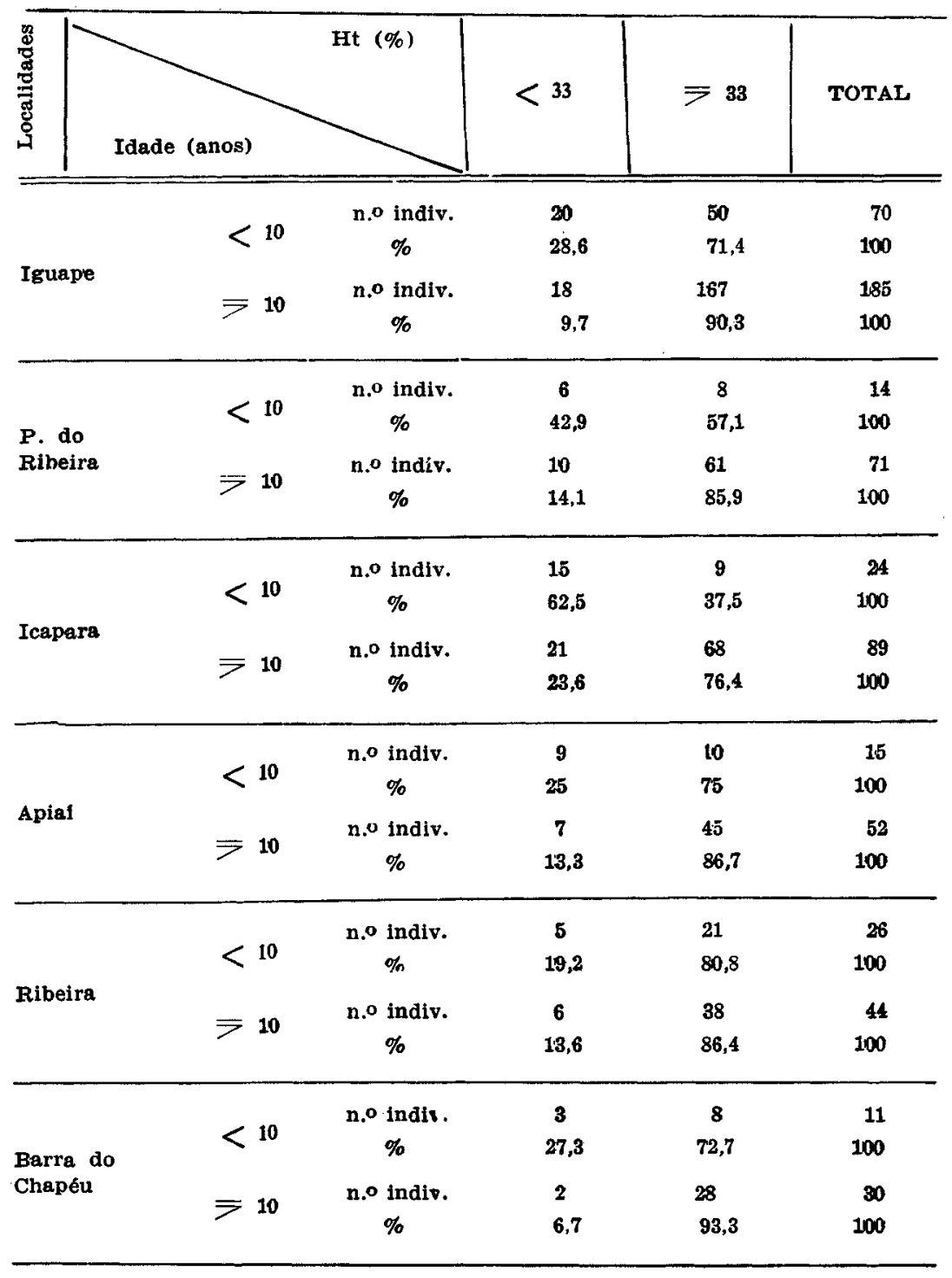


SZaRfarC, S. C. - Anemla ferropriva em populaçбes da regiăo sul do Estado de São Paulo. Rev. Saúde públ., S. Paulo, 6:125-33, 1972.

Os resultados obtidos nas dosagens de ferro sérico e de capacidade de ligação de ferro (Tabelas 6 e 7) foram distribuí- dos de acordo com o critério adotado pelo Chemical Methods of Medical Investigation Merck*.

T A B E L A 6

Níveis de ferro sérico nas comunidades do Vale do Ribeira, 1969 e 1970.

\begin{tabular}{|c|c|c|c|c|c|c|c|c|c|c|c|c|}
\hline Localidades & & & $\begin{array}{r}\text { Pon } \\
\text { Ril }\end{array}$ & $\begin{array}{l}\text { do } \\
\text { ira }\end{array}$ & & para & & oíai & & gira & $\begin{array}{r}\text { Bar } \\
\text { Ch }\end{array}$ & $\begin{array}{l}\text { do do } \\
\text { péu }\end{array}$ \\
\hline Nivel & n.o & $\%$ & n.o & $\%$ & n.o & $\%$ & n.o & $\%$ & n.o & $\%$ & n.o & $\%$ \\
\hline $\begin{array}{l}\text { Muito baixo } \\
\text { e baixo }\end{array}$ & 60 & 33 & 21 & 36 & 39 & 49 & 10 & 20 & 14 & 29 & 9 & 24 \\
\hline Normal & 70 & 38 & 27 & 47 & 31 & 39 & 23 & 46 & 25 & 52 & 18 & 48 \\
\hline Alto & 52 & 28 & 10 & 17 & 10 & 12 & 17 & 34 & 9 & 19 & 11 & 29 \\
\hline TOTAL & 182 & 99 & 58 & 100 & 80 & 100 & 50 & 100 & 48 & 100 & 38 & 101 \\
\hline
\end{tabular}

TABELA 7

Capacidade de Ligaçăo de ferro nas comunidades do Vale do Ribeira, 1969 e 1970.

\begin{tabular}{|c|c|c|c|c|c|c|c|c|c|c|c|c|}
\hline \multirow[t]{2}{*}{ Localidades } & \multicolumn{2}{|c|}{ Iguape } & \multicolumn{2}{|c|}{$\begin{array}{c}\text { Pontal do } \\
\text { Ribeira }\end{array}$} & \multicolumn{2}{|c|}{ Icapara } & \multicolumn{2}{|c|}{ Apiaí } & \multicolumn{2}{|c|}{ Ribeira } & \multicolumn{2}{|c|}{$\begin{array}{c}\text { Barra do } \\
\text { Chapéu }\end{array}$} \\
\hline & n.o & $\%$ & n.o & $\%$ & n.o & $\%$ & no & $\%$ & $n .0$ & $\%$ & n.o & $\%$ \\
\hline Baixo & 3 & 2 & 1 & 2 & 0 & 0 & 6 & 12 & 10 & 25 & $\mathbf{5}$ & 14 \\
\hline Normal & 55 & 31 & 22 & 33 & 14 & 18 & 21 & 42 & 18 & 37 & 19 & 51 \\
\hline Alto & 120 & 67 & 43 & 65 & 64 & 83 & 23 & 46 & 18 & 37 & 13 & 35 \\
\hline TOTAL & 178 & 100 & 66 & 100 & 78 & 101 & 50 & 100 & 48 & 99 & 37 & 100 \\
\hline
\end{tabular}

Através do inquérito alimentar levado a efeito na mesma amostra da população, na mesma época, pudemos conhecer a ingestação média "per capita" diária de ferro, através dos diferentes alimentos $2,4,8$.
O consumo de ferro relacionado às recomendações diárias para a mesma população 6 está expresso na Tabela 8.

\footnotetext{
* Merckotest - artigo n.o 3307 - Ferro

Merckotest - artigo n.o 3313 - Capacidade de combinação com o ferro.
} 
SZARFARC, S. C. - Anemia ferropriva em populações da região sul do Estado de São Paulo. Rev. Saide puibl., S. Paulo, 6:125-33, 1972.

TA B ELA 8

Recoinendação e consumo - por đia - de ferro na amostra populacional estudada, 1969 e 1970.

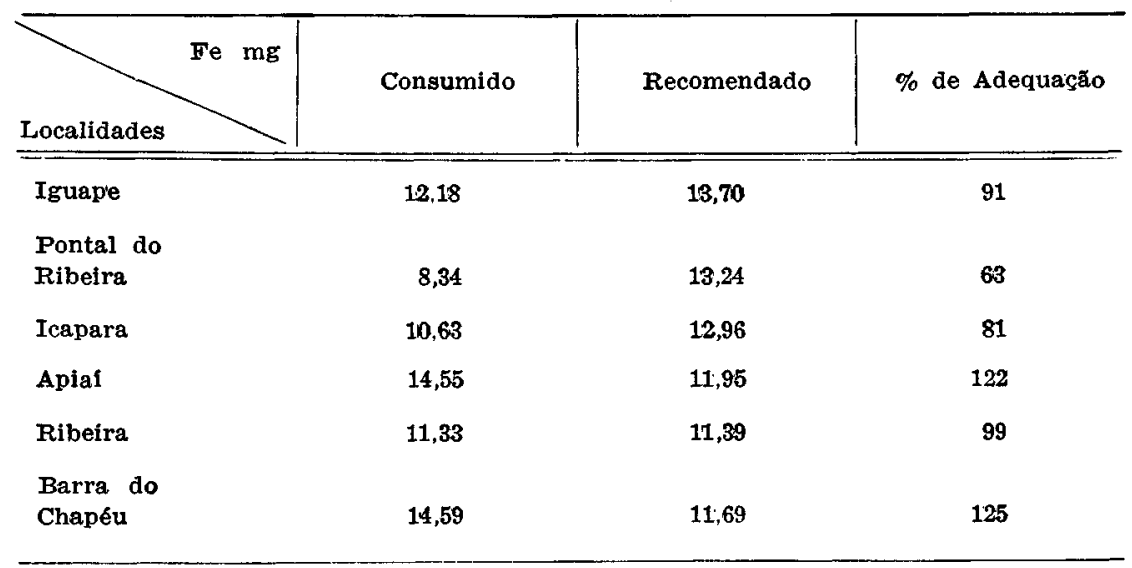

\section{COMENTARIOS}

Acreditamos que a inexistência de saneamento básico condicione as infestações parasitárias as quais justificariam a maior incidência de anemia ferropriva, encontrada nas crianças do grupo etário menor do que 10 anos, nas localidades de Pontal do Ribeira e Icapara, em relação às outras localidades estudadas. Em Barra do Chapéu, não se evidenciou anemia ferropriva através do indicador hemoglobina, embora nessa localidade os recursos de assistência médico-sanitária sejam equivalentes aos de Pontal do Ribeira e Icapara.

Com a abertura do mercado de trabalho no município de Apiai, está havendo grande afluxo de pessoas de baixo poder aquisitivo para esse município e que aí se instalam em condições precárias. Esse crescimento não homogêneo da população, sem uma concomitante extensão da rede de água e esgotos e expansão dos serviços de saúde da localidade, torna possível uma previsão de variações dos níveis hematológicos da população, quando comparados ulteriormente com as médias encontradas nesta pesquisa.
Isso sugere a necessidade de planejamento de programas para cada localidade de "per si", levando-se em conta suas características próprias. Como vimos, nem a proximidade geográfica, nem as semelhanças de infraestrutura permitem que se infira para outras comunidades.

Analisando os aspectos da ingestão e absorção do ferro, cumpre-nos ressaltar que o conhecimento da adequação do consumo desse mineral é pouco significativo. Tendo sido família a unidade amostral do inquérito alimentar, cujos dados utilizamos, não nos foi possível relacionar, para cada indivíduo, consumo de ferro e níveis hematológicos.

$O$ inquérito alimentar não levou em consideração o ferro ingerido através da água, impurezas e utensílios usados no preparo dos alimentos.

Outro aspecto que convém ser lem. brado quando se enfoca a absorção do ferro, relaciona-se com os fatores que interferem nessa absorção. LAYRISSE et al. 3 evidenciaram que a absorção do ferro é maior quando a ingestão do mes- 
SZARFARC, S. C. - Anemia ferropriva em populaçóes da regiăo sul do Estado de São Paulo. Rev. Saúde públ., S. Paulo, 6:125-33, 1972.

mo é concomitante com a de proteinas de origem animal. MAZZILLI ${ }^{5}$, refere que o consumo de proteínas de origem animal é adequado em Pontal do Ribeira e Icapara, evidentemente, por serem regiốes pesqueiras. Entretanto, nessas localidades foi evidenciado baixo consumo de ferro e a prevalência de anemia ferropriva, constituindo grave problema de saúde pública.

\section{CONCLUSOOS}

1. Em Pontal do Ribeira e Icapara encontramos as maiores prevalências de anemia ferropriva.

Em Apiaí, Ribeira e Iguape, foi menor a $\%$ de indivíduos nos quais se detectou esse tipo de anemia.

Em Barra do Chapéu, contrariamente ao que era de se esperar - devido à falta de recursos médico-sanitários - não se encontrou anemia ferropriva utilizando o indicador hemoglobina, tendo sido muito baixa quando se utilizou o indicador hematócrito.

2. Em crianças do grupo etário menor do que 10 anos, nas comunidades de Icapara e Pontal do Ribeira, há maior frequiência de valores de hemoglobina menores do que $12 \mathrm{~g} \%$ e de hematócrito menores que $33 \%$.

3. Em Icapara, o ferro sérico foi abaixo do normal em $49 \%$ da população.
4. Nas seis localidades estudadas foi encontrada alta porcentagem de indivíduos com capacidade de ligação de ferro maior do que o normal.

5. A ingestão de ferro através de alimento correspondente a $96 \%$ das necessidades da população de Iguape, $63 \%$ de Pontal do Ribeira, $81 \%$ de Icapara, $122 \%$ de Apiai, $99 \%$ de Ribeira e $125 \%$ de Barra do Chapéu.

RSPSP-124

Szarfarc, S. C. - [Iron deficiency anae mia in populations of the Southern area of the State of S. Paulo, Brazil]. Rev. Saúde públ., S. Paulo, 6:125-33, 1972.

Summary: A study of iron deficiency anaemia in seaside and mountain population of the southern area of the state of S. Paulo, Brazil, was carried out. The towns studies were, Iguape, Pontal do Ribeira, Icapara, Apiai, Ribeira and Barra do Chapeu.

Studying the composition of food-stuff consumed a "per capita" average iron consumption was stablished for each town. Results showed that consumption of iron in Iguape was 91\% of minimum needs, Pontal do Ribeira, 63\%, Icapara, $81 \%$, Apiai, 122\%, Ribeira, 99\% and Barra do Chapeu, $125 \%$.

It was found that in most localities iron deficiency anaemia constitutes a public health problem.

Uniterms: Anaemia, deficiency*; Population*; S. Paulo, Brazil*. 
SZARFARC, S. C. - Anemia ferropriva em populaçōes da região sul do Estado de São Paulo. Rev. Saúde públ., S. Paulo, 6:125-33, 1972.

\section{REFERENCIAS BIBLIOGRAFICAS}

1. BOTWELL, T. H. \& MALLET, B. - The determination of iron in plasma or rum. Biochem. J., 59:599-602, 1955.

2 FRANCO, G. - Tabela de composigao qui mica dos alimentos. Rio de Janeiro, Ser. viço de Alimentação da Previdência Social, 1959.

3. LAYRISSE, M. et al. - Effect of interaction of various foods on iron absorption. Amer. J. Clin. Nutr., 21:1175-83, 1968.

4. LEUNG, W. T. W. \& FLORES M. - Tabla de composioion de alimentos para uso en América Latina. Guatemala, Instituto de Nutrición de Centro-América y Panamá, 1961.

5. MAZZILLI, R. N. - Algumas considerações sobre o consumo de alimentos em Ica para e Pontal apud CONGRESSO BRA. SILEIRO DE HIGIENE, 18.0, Să Pau1o, 1970. São Paulo, 1970. p. 122.

6. NATIONAL ACADEMY OF SCIENCES Recommended dietary allowances, 1968. São Paulo, SP, Produtos Nestle, gd. (Comunicação de nutrição, 2).

7. SCHADE, A. L. et al. - Bound iron and unsaturated iron-binding capacity of serum; rapid and reliable quantitative determination. Proc. Soc. exp. Biol. (N. $Y$.), 87:443-8, 1954 .

8. UNIVERSIDADE SAO PAULO. Faculdade de Saúde Pública. Departamento de Nutrição. Tabela de composição dos alimentos. Compilagão de diferentes tabelas. São Paulo, 1970.

Recebido para publicaçāo em 16-8-1971

Aprovado para publicagao em 25-4-1971 